Report No. BMI-1405

UC-38 Equipment, Methods, and Techniques (TID-4500, 15th Ed.)

Contract No. W-7405-eng-92

\title{
BEHAVIOR OF RUBBING MOLYBDENUM SURFACES IN SODIUM ENVIRONMENTS
}

by

John W. Kissel

Carl W. Melton

William A. Glaeser

January 4, 1960

BATTELLE MEMORIAL INSTITUTE

505 King Avenue

Columbus 1, Ohio 


\section{DISCLAIMER}

This report was prepared as an account of work sponsored by an agency of the United States Government. Neither the United States Government nor any agency Thereof, nor any of their employees, makes any warranty, express or implied, or assumes any legal liability or responsibility for the accuracy, completeness, or usefulness of any information, apparatus, product, or process disclosed, or represents that its use would not infringe privately owned rights. Reference herein to any specific commercial product, process, or service by trade name, trademark, manufacturer, or otherwise does not necessarily constitute or imply its endorsement, recommendation, or favoring by the United States Government or any agency thereof. The views and opinions of authors expressed herein do not necessarily state or reflect those of the United States Government or any agency thereof. 


\section{DISCLAIMER}

Portions of this document may be illegible in electronic image products. Images are produced from the best available original document. 
ABSTRACT。................................. 1

INTRODUCTION • • . . . . . . . . . . . . . . . . . . . . 1

RESEARCH PROGRAM 。 • . . . . . . . . . . . . . . . . . . 2

Slow-Speed Friction Apparatus . . . . . . . . . . . . . . . 2

Preliminary Rubbing-Surface Experiments . . . . . . . . . . . 4

Study of Molybdenum Rubbing Against Molybdenum . . . . . . . . 9

Specimens . . . . . . . . . . . . . . . . . 9

Experimental Results of Friction Studies. . . . . . . . . . 10

Surface-Film Investigation . . . . . . . . . . . . . . 10

Posttest Analysis of Friction Specimens . . . . . . . . . . . . 15

DISCUSSION • • • . • . . . . . . . . . . . . . . . . . . . 21

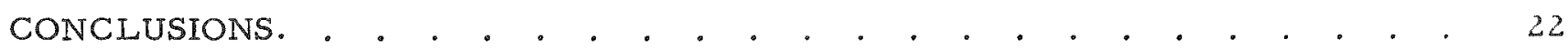

REFERENCES. • . . . . . . . . . . . . . . . . . . . 23 


\section{BEHAVIOR OF RUBBING MOLYBDENUM SURFACES IN SODIUM ENVIRONMENTS}

John W. Kissel, Carl W. Melton, and William A. Glaeser

A study has been made of the wear and friction phenomena associated with sliding molybdenum surfaces lubricated by liquid sodium. Operating conditions included sodium temperatures from $250 \mathrm{~F}$ to $1300 \mathrm{~F}$, sliding speeds of from 0.22 to $2.5 \mathrm{~mm}$ per sec, and contact stresses of $80,000 \mathrm{psi}$. Sliding specimens consisted of a ball and a flat rectangle.

Sodium u'as found to influence the sliding behavior of molybdenum by modifying reacted films which provided boundary lubrication. These effects were also found to be temperature dependent. Addition of clean sodium between dry rubbing molybdenum surfaces in an argon atmosphere of high purity produced a marked drop in fricsion coefficient, and the character of the wear scar changed from galling to superficial scratching. Furthermore, these effects persisted after removal of sodium by evaporation.

Studies of the films formed on molybdenum surfaces during sliding in liquid sodium and under controlled atmospheres were carried out using electron and 1 -ray diffraction, electron microsrope, and differential thermal-analysis techniques. It u'as established that a sodium molybdate film on the molybdenum surfaces can be associated with low friction and diminished surface damage. Siudies in vacuums up to $10^{-6} \mathrm{~mm}$ of mercury showed that native oxides on molybdenum also influence its sliding behavior.

\section{INTRODUCTION}

During the past few years there has been increasing interest shown in the use of sodium and sodium-potassium alloys, as heat-transfer media in the field of nuclearpower generation. This interest was stimulated by the need to remove large quantities of heat from nuclear-power reactors at moderate coolant velocities and convective film temperature drops. Liquid alkali metals possess many desirable characteristics for this purpose, such as: low vapor pressures, low viscosities, high boiling points, high thermal conductivities, and good radiation stability. These properties permit lowpressure operation of coolant systems at high temperatures and radiation fluxes. On the other hand, the extreme chemical activity of the alkali-metal group presents unusual design and handling problems. In design, the primary consideration is selection of materials which are not attacked by molten alkali metal and which do not react with, or adhere to, one another under the proposed operating conditions. These requirements must be met in addition to those usually experienced for high-temperature operation of rubbing components. The use of molten alkali metals in engineering systems has led to development of a whole new technology for the purpose of safely and efficiently handling these highly reactive liquids; and, although much equipment has been designed, tested, and built to handle liquid sodium, no dependable design rules have yet been developed to guarantee that the next pump, valve, etc., will perform satisfactorily. 
In the application of any heat-transfer fluid, means must be found to produce and regulate the flow between the zone where heat is being produced and the zone where heat is being utilized. The rubbing surfaces of pumps and valves required to effect these ends and the submerged mechanisms involved in control-rod and fuel-element handling in alkali-metal systems have employed materials which demonstrated good strength, corrosion resistance, and rubbing compatibility during screening-type tests. This empirical approach, directed toward specific application problems, has produced no data having general application to a large number of different situations. Clearly then, design rules of general application are needed in this area before powergenerating reactors are designed for the higher coolant temperatures required for competitive operation with conventional plants.

\section{RESEARCH PROGRAM}

To develop the general principles considered important in selection of materials and in mechanical design of components, an approach was adopted in which friction phenomena occurring between pairs of materials rubbing while immersed in liquid sodium were investigated. Both the frictional behavior and the condition of sliding surfaces before and after sliding under controlled conditions were carefully studied since it is known that the condition of friction surfaces plays an important role in wear and frictional behavior.

\section{Slow-Speed Friction Apparatus}

The sliding behavior of a ball specimen moving slowly across a flat specimen was studied through use of the apparatus illustrated in Figure 1. (The ball-on-a-flat specimen configuration was chosen to avoid surface-alignment problems.) This drawing shows how a long, flat, vertically mounted spring is employed to support and align the upper (ball) specimen while at the same time providing a restoring force for the friction being measured. The long rod, which connects the ball specimen to the lower (movable) end of the spring, isolates the heated test section from the calibrating spring and the linear variable differential transformer assembly. The latter senses the instantancous position of the ball and relays the signal to a continuous-recording device.

Movement between the two specimens is obtained by axially moving the lower (flat) specimen support rod through a pair of ball bushings. Uniform linear motion is produced by a low-voltage d-c motox acting through a gear reducer coupled to a leadsrew drive. Various combinations of motor-gearhead units and lead-screw pitches provide a wide choice of rubbing speeds. The lower specimen holder is also arranged so that it can be moved laterally a small measured distance, between sliding experiments, without opening the apparatus. By this means, a new surface area of the flat specimen can be traversed by the ball whenever desired.

Maximum Hertzian stress at the contact area between specimens is dependent upon the vertical loading, which can be varied by adjusting both the size and position of the variable load along the upper specimen arm, or by using a ball specimen of different diameter. Matching the maximum spring deflection - determined by the 


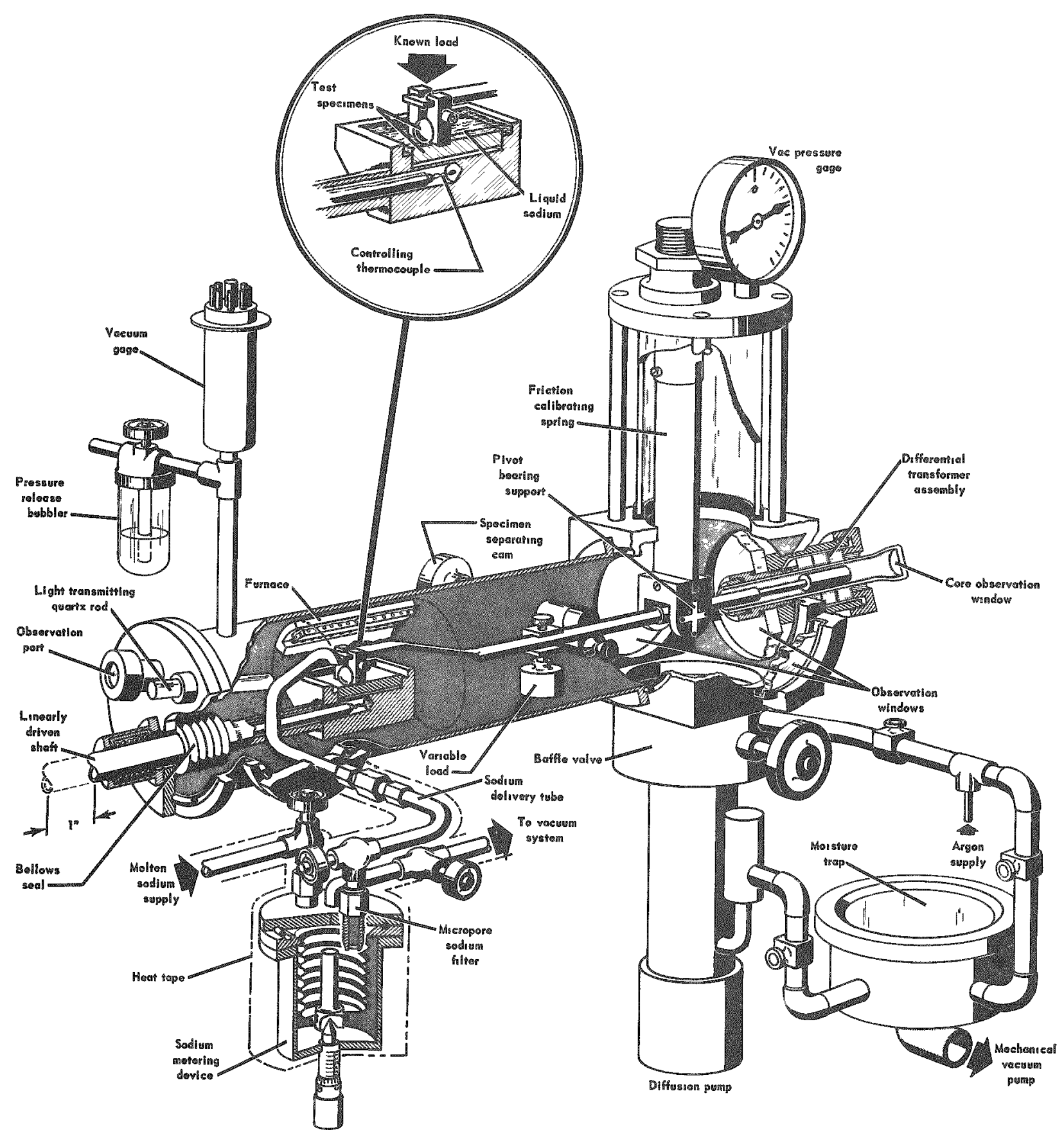

FIGURE 1. STICK-SLIP SLOW-SPEED FRICTION-EVALUATION APPARATUS FOR LIQUID-SODIUM LUBRICATION STUDIES 
maximum frictional force - to the maximum linear range of the transformer is accomplished by choosing a spring of the proper thickness and length.

The entire sliding and friction-measuring mechanism is enclosed in a sealed stainless steel housing. This is connected to a high-vacuum system and to an inert-gas supply. All the bulkhead and rod seals are of rubber or Teflon O-rings. Linear motion for the lower specimen holder is through a welded bellows connection. The differential transformer core operates inside a closed glass tube which isolates it from the atmosphere. Because of this elaborate system of seals, absolute pressures below $1 \times 10^{-5}$ $\mathrm{mm}$ of mercury can be achieved routinely. Cold-trapped zirconium-gettered sodium obtained in stainless steel containers is used for the friction experiments. It is transferred via argon-filled, heated, stainless steel tubing and fittings to the metering device illustrated at the lower left of Figure 1. From there, the sodium is forced (by compressing the bellows) through a stainless steel Micropore filter and into the frictiontest region where it is deposited, dropwise, onto the lower specimen. Temperature of the test specimens is maintained with an accuracy of $\pm 10 \mathrm{~F}$ by means of a furnacecontrolling thermocouple embedded in the lower specimen holder. Cooper cooling coils carrying water are required to cool the outer housing near the O-ring seals.

\section{Preliminary Rubbing-Surface Experiments}

Friction under dry and oil-lubricated conditions was recorded for several materials in order to furnish baseline data for comparison with data from experiments employing sodium-lubricated conditions. Considerable variation in the general character of recorded friction traces was observed. This is evidenced in its extremes by Figures 2 and 3. The several traces of Figure 2 illustrate a type of sliding which seems to result from friction between residual surface films attached to the specimen surfaces; those of Figure 3 illustrate the marked stick-slip behavior commonly associated with boundary lubrication conditions. These illustrations also demonstrate the reproducibility obtained for forward and reversed sliding. The four traces shown in Figure 2 were produced by moving the lower specimen in the directions indicated. The original chart traces were photographically copied, then arranged on a single displacement (time) scale, in order to clearly illustrate the remarkable reproducibility of both gross and fine structure. Figure 3 (and also Figures 4 and 5) are photographs of friction traces as obtained on the recorder chart. That a characteristic structure, different for different specimens, is reproduced irrespective of the direction of specimen travel is an indication that it is a true manifestation of the friction between the rubbing surfaces and not merely a reflection of the peculiarities of the machine. Sometimes a change in the character of the friction trace is observed during the course of a single slide over the test surface: notice the decreasing friction values shown in Figure 4a. This appears to be the result of a modification of the small rubbing area on the ball specimen. Figure 4 b illustrates the damped oscillation which occurs at the end of a large slip. This is produced by the normal override of the calibrating spring.

To obtain coefficient-of-friction data, shown plotted in Figure 5, the following procedure is followed: By inspection, a line is drawn, parallel with the central, zeroposition line which bisects the maximum and minimum points on the recorded curve (e.g., the 0.4 lines marked on Figure 2). The position of this line, with respect to the central zero-line is related, by means of a previously prepared calibration chart, to an appropriate number of grams of horizontal deflection. This value is next averaged with 


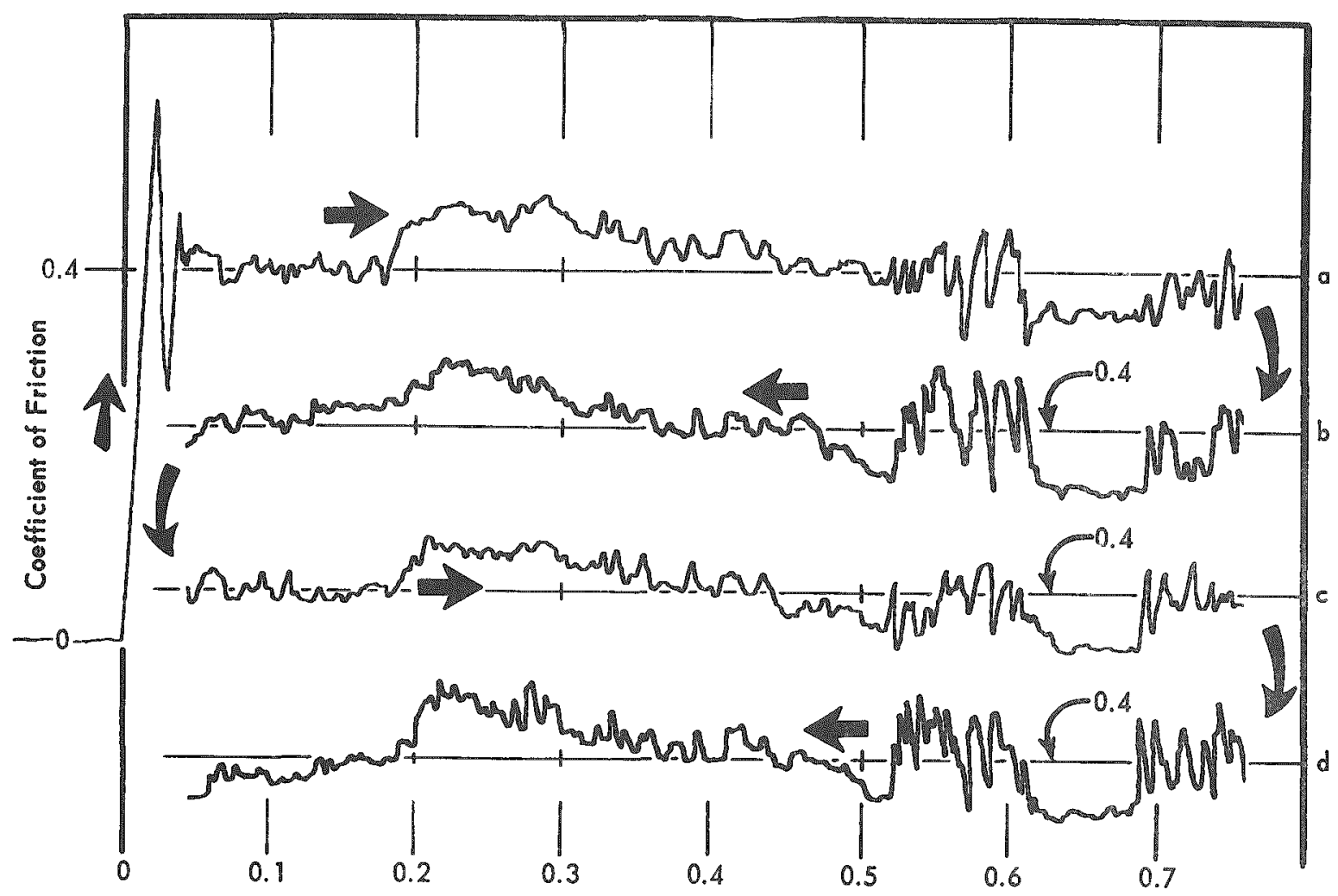

Linear Displacement, inch

FIGURE 2. FRICTION VERSUS DISPLACEMENT ALONG SLIDE PATH

The friction traces designated a and $c$ are for forward motion and those designated $b$ and $d$ are for reversed motion.

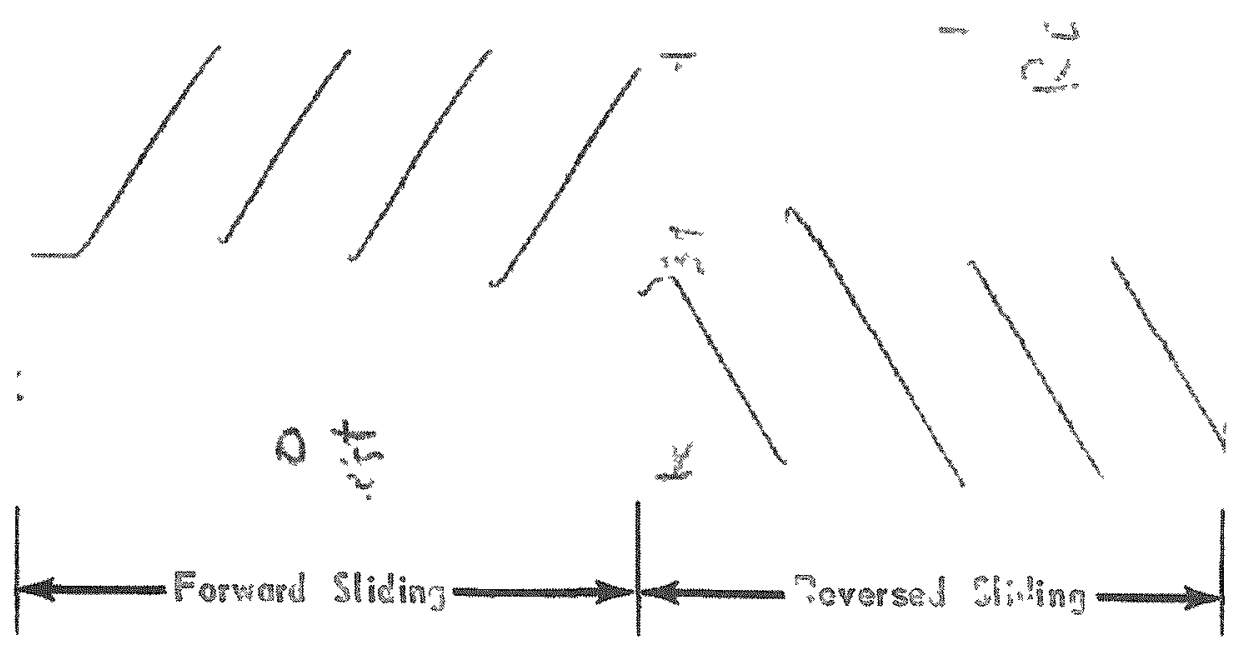

FIGURE 3. STICK-SLIP FRICTION TRACES

Sliding proceeds by a series of alternating "sticks" and "slips". During "slips", for example, actual sliding speeds of $250 \mathrm{~mm}$ per sec were recorded whereas the specimen movement was only $0.25 \mathrm{~mm}$ per sec. Low specimen speeds, high contact pressures, and low restoring-spring rates intensify stick-slip behavior. 


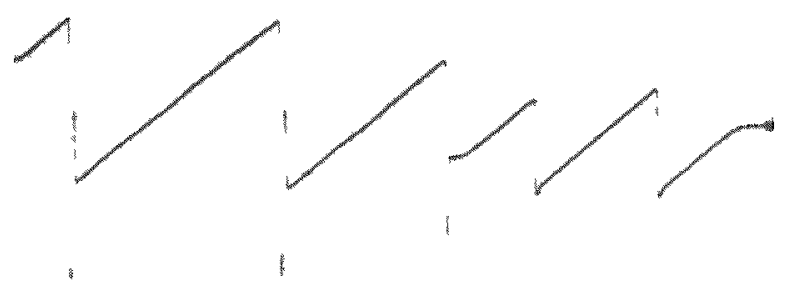

a. Stick-slip behavior for a unidirectional run

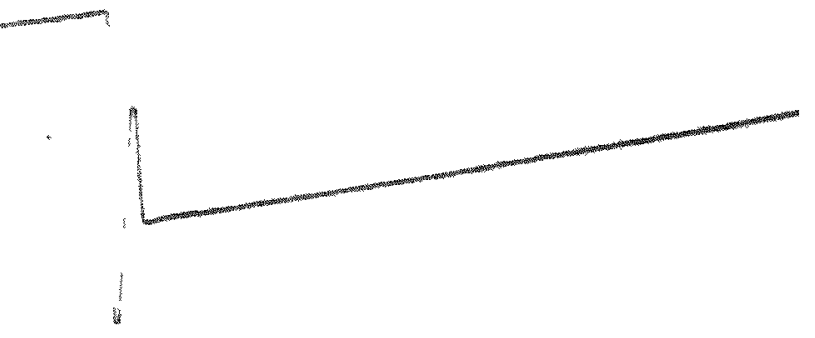

b. Detail of a single slip

FIGURE 4. CHARACTERISTICS OF THE STICK-SLIP BEHAVIOR 


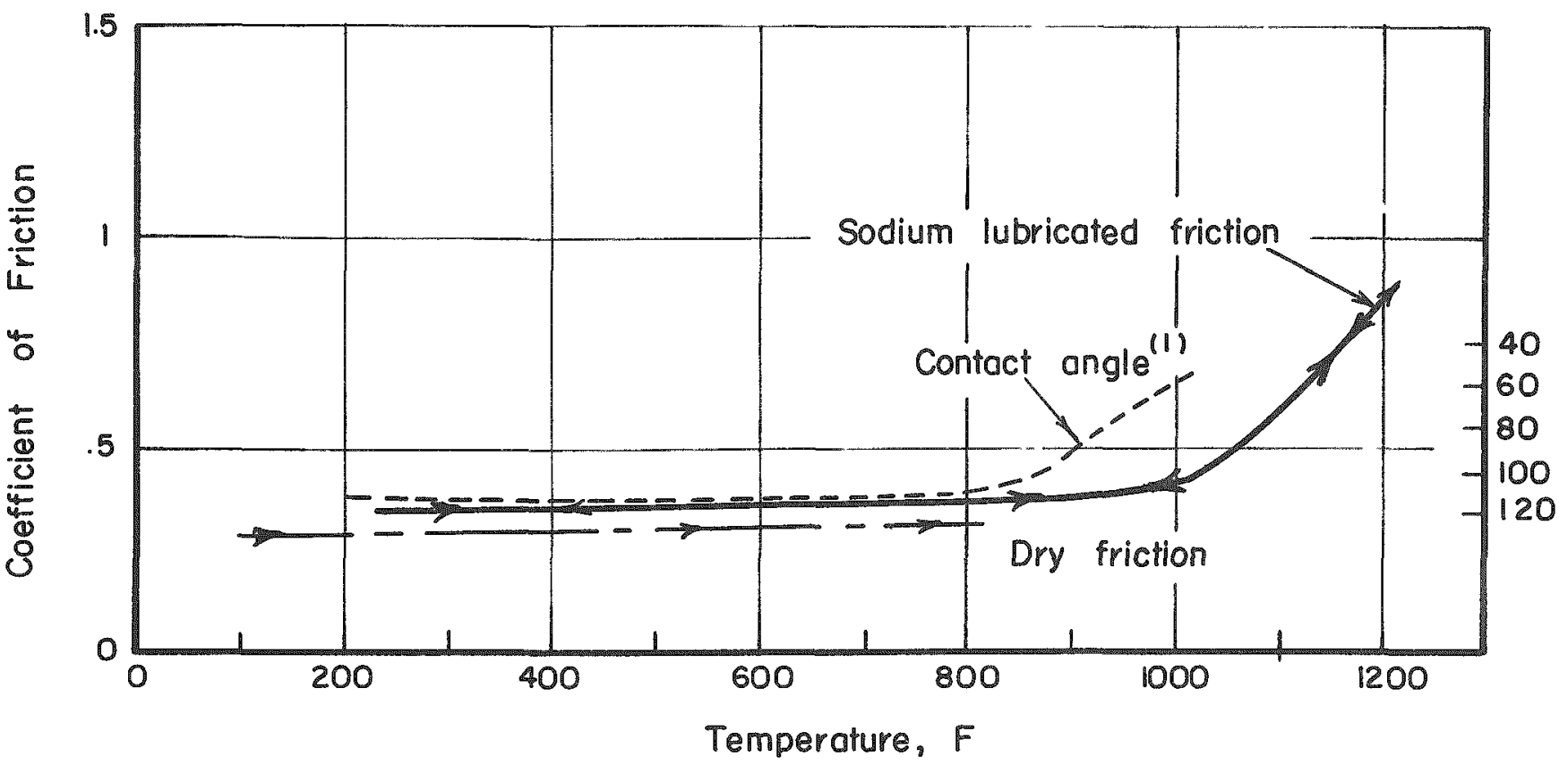

a. Tungsten carbide $-20 \mathrm{w} / 0$ cobalt binder versus itself

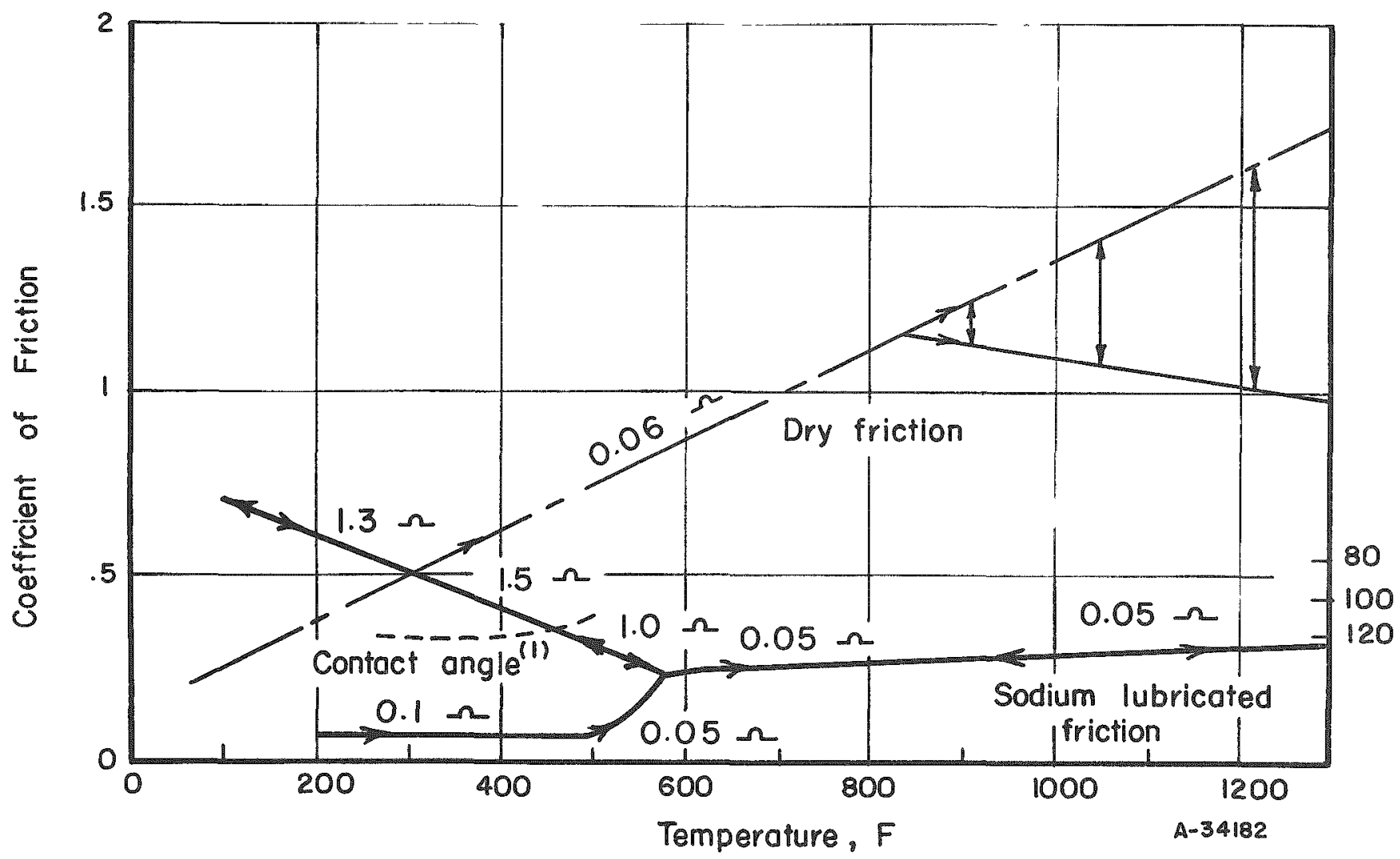

b. Molybdenum versus itself

FIGURE 5. FRICTION DATA AND WETTABILITY DATA COMPARED 
similarly obtained gram values for reversed and repeated runs. The resultant number of grams is divided by the experimentally measured vertical load, to obtain an average coefficient of kinetic friction. The static friction, represented by the peak value of each stick cycle, was not discernible in all types of friction traces (e.g., Figure 2); consequently, it was not routinely measured.

The experimentally obtained coefficients, shown plotted in Figure 5, show the friction-versus-temperature trends. Data for the dry-friction curves were obtained first in both of the illustrated runs. That of Figure $5 b$ shows increasing data scatter at temperatures above about $800 \mathrm{~F}$. This behavior might be expected from the breakdown or removal of a residual protective film. Following these friction tests conducted without lubrication, sodium was added to the lower specimen surface and the remainder of the recorded data obtained. The direction of temperature changes is indicated by arrowheads superimposed upon the friction curves. Where the arrowheads point in both directions on the same line, the curve indicates that coefficients of friction are "eproduced during both rising and falling temperature cycles. For example, Figure 5b illustrates for molybdenum suxfaces a low friction from 200 to $500 \mathrm{~F}$, a sharp increase in friction above $550 \mathrm{~F}$, little change from 550 to $1300 \mathrm{~F}$, and, finally, a fairly rapid increase for temperatures below the original point of friction increase. This behavior suggested the occurrence of a nonreversible chemical reaction between 500 and $600 \mathrm{~F}$.

Simultaneous records were made of contact resistance by electrically insulating the two specimens and emplojing a low-voltage alternating-current bridge cir'cuit and stick-slip friction to see if changes in the nature of the surface-to-surface contact during stick-slip could be deduced. A sample recording from a representative chart is shown in Figure 6. The striking similarity in the two curves show that surface factors which contribute to contact-resistance changes apparently also influence friction behavior. It can be scen in Figure 6 that, during the stick portion of the friction trace, contact resistance continuously decreases. It is presumed this relationship indicates that, as the shearing force increases, the junctions of metal-to-metal contact are spread out and the total contact area made larger, increasing the conductance. The ball is apparently "digging into" the flat surface and mounding it up at the leading edge of the ball. Just before slip, the contact resistance levels out, and suddenly increases indicating a stretching of contact points and, finally, breaking of the contacts and sliding. Each slip is accompanied by a "peak" in the contact resistance.

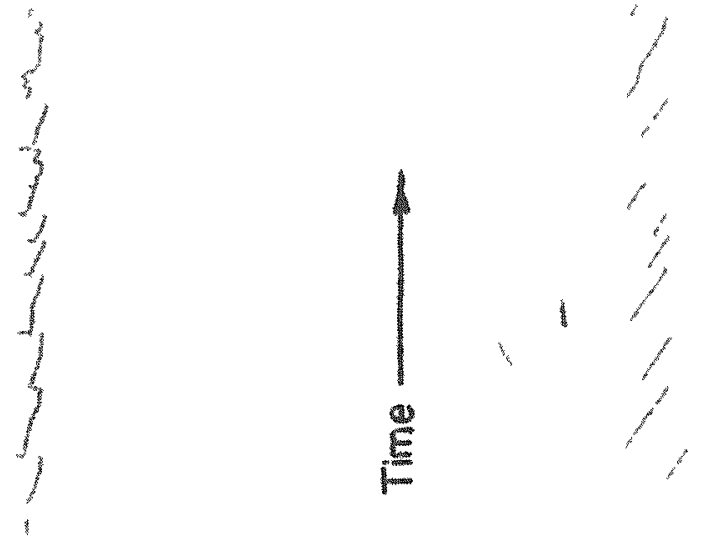

FIGURE 6. SIMULTANEOUS RECORD OF STICK-SLIP FRICTION AND CONTACT RESISTANCE 
Contact-resistance measurements are indicated at appropriate points along the friction curve of Figure 5b. Contact resistance consistently dropped to a steady value of $0.05 \mathrm{ohm}$ when the specimen temperature reached and passed $500 \mathrm{~F}$. This value was similar to contact resistance measured under dry sliding conditions. The drop in contact resistance at a given temperature in sodium-lubricated sliding was considered indicative of wetting of the surfaces by the sodium.

The results from the two tests, illustrated in Figure 5, show very different frictional behavior for $\mathrm{WC}-20 \mathrm{w} / \mathrm{o}$ cobalt as compared with molybdenum specimens. For the cermet, under a calculated average stress of 98,500 psi, the presence of molten sodium was not accompanied by a decrease in sliding friction. The average stress is believed to provide a more accurate description of conditions existing for the ball, plate, specimen configuration; it has a value approximately two-thirds that of the maximum compressive stress. The molybdenum, however, under an average compressive stress of 83,300 psi, demonstrated considerably lower friction, especially at the higher temperatures, when sodium was present at the sliding interface.

Study of Molybdenum Rubbing Against Molybdenum

Following the preliminary experiments in which the functioning of the frictionmeasuring apparatus was evaluated, a decision was made to limit the succueding research phase to an intensive study of factors affecting friction and wear between molybdenum specimen pairs only. The reasons for selecting molybdenum were as follows:

(1) Molybdenum has recognized high strength and hardness at elevated temperatures.

(2) It has demonstrated good high-temperature corrosion resistance to molten alkali metals.

(3) It has demonstrated relatively little tendency to self-weld when immersed in high-temperatuxe alkali metal for long periods.

(4) Preliminary friction evaluations with molybdenum revealed certain unique behavior patterns which were associated with probable surface-filming phenomena. Molybdenum also demonstrated low friction characterjstics under certain conditions of operation.

(5) The use of single-phase polycrystals as specimens would provide a metallurgical system much less complex to evaluate than might be presented by use of special alloys or cermets.

\section{Specimens}

The 1/4-in. polished molybdenum balls used for these experiments were obtained in a single batch. All of the molybdenum flat specimens likewise were made from a single piece of hot-rolled (one direction) molybdenum plate. Metallographic 
analysis indicated the flat material contained numerous oxide and/or carbide inclusions. It was chosen, however, because the total a mount of such impurities was much less than that found in several other samples. The preparation of the friction-test flats was as follows: After specimens were machined and ground to size, one surface was lapped, with Carborundum and diamond dust, to a surface smoothness of 6 to $10 \mu \mathrm{in}$. rms. An electron micrograph of the lapped surface, shown in Figure 7, revealed numerous lapping scratches and pits located below the plane of lapping. After lapping, the specimens were washed in detergent solution followed by organic solvents; then they were extracted in a trichloroethylene vapor degreaser for at least $30 \mathrm{~min}$. One half of the specimen was then immersed in Murakami's etchant ( $10 \mathrm{~g}$ of potassium ferricyanide, $10 \mathrm{~g}$ of potassium hydroxide, and $100 \mathrm{~cm}^{3}$ water) for $3 \mathrm{~min}$ at room temperature. A light photomicrograph, Figure 8, and an electron micrograph, Figure 9, show the appearance of the etched surface. Stress cracks were observed in the elched molybdenum surface and can be seen in Figures 8 and 9. In general, these cracks were oriented perpendicular to the direction of grain elongation. The propagation of these stress cracks from the grain boundaries is apparent in Figure 9.

Experimental Results of Friction Studies

An extensive series of friction experiments (several hundred separate runs) was performed with molybdenum specimens. Both dry sliding and sodium-lubricated sliding were investigated over a range of temperatures from $250 \mathrm{~F}$ to $1300 \mathrm{~F}$.

Dry-rubbing experiments were made to study the influence of surface conditioning of the lapped molybdenum by exposure to various temperatures for given periods of time in controlled gaseous environments. The data from these experiments are summarized in Figure 10. The curves in Figure 10 demonstrate the influence of time at temperature on the friction of molybdenum. It also shows a tendency for friction to decrease above $1000 \mathrm{~F}$, presumably from a thermal softening of surface layers.

When the gaseous environment was removed and the specimens rubbed in a partial vacuum the friction decreased. Prolonged heating in the vacuum, which might be expected to remove films which prevent metal-to-metal contact, unexpectedly resulted in a decrease in friction.

Sodium-lubricated runs, summarized in Figure 11 , showed that data scatter partially accounted for the apparent discontinuities in the friction-versus-temperature relationships determined during the initial series of experiments (Figure $5 \mathrm{~b}$ ). The friction data illustrated in Figure 11 demonstrate the significance of a specimen's history (surface preparation and length of time of exposure to various environments). Friction runs made successively at a given temperature demonstrated insignificant variations in friction; but when a whole series of runs, involving the complete temperature range up to $1300 \mathrm{~F}$, was repeated, the values for coefficient of friction might vaxy considerably. Such phenomena seem most easily understood in terms of changes which occur in surface conditions over a period of time.

\section{Surface-Film Investigation}

Concurrently with the friction experiments, an analytical program, designed to explore the nature of the surface films present under given conditions, was carried out. Surface-reflection electron-diffraction analyses indicated that $\mathrm{MoO}_{3}$ is formed on 


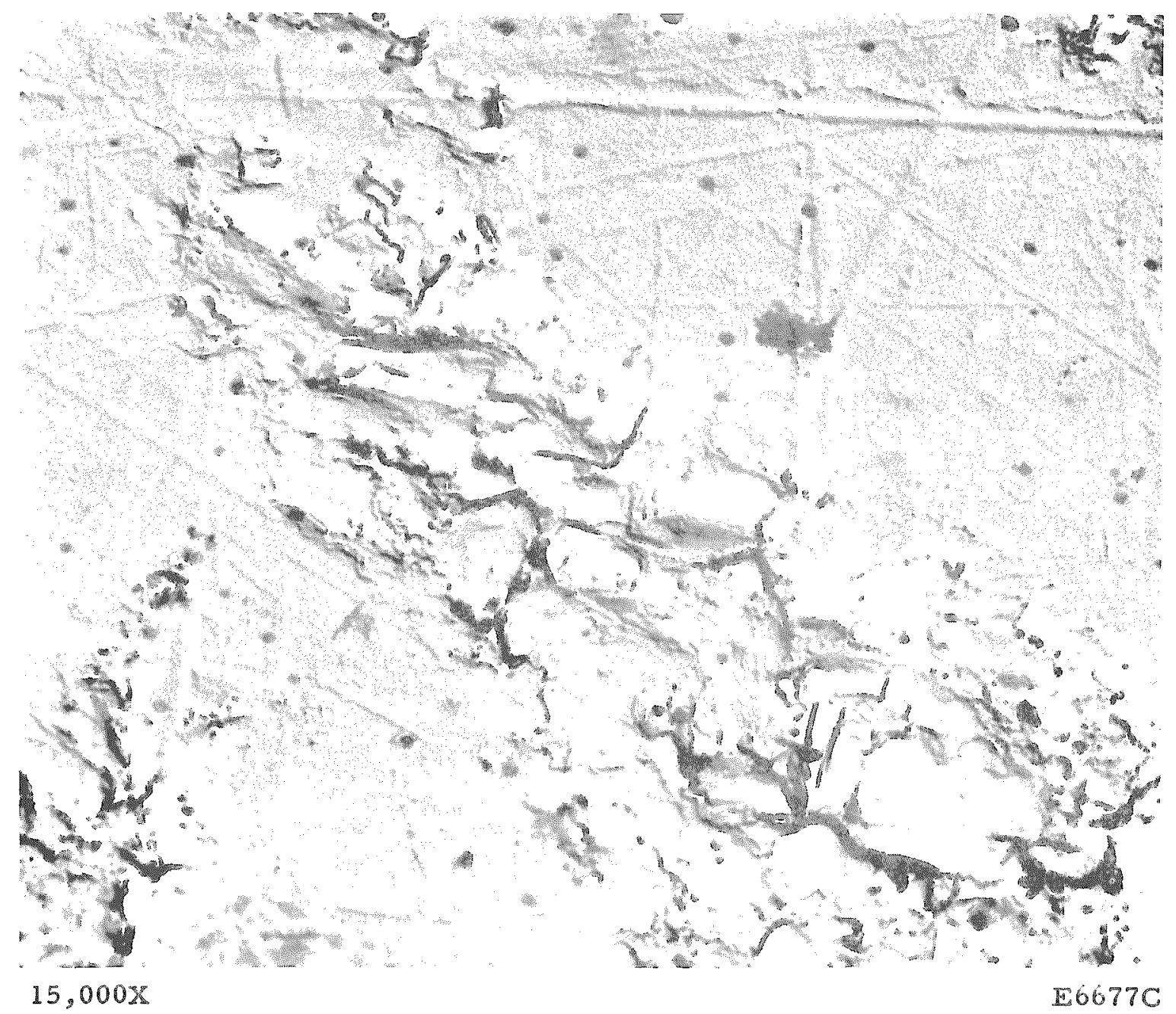

FIGURE 7. ELFCTRON MICROGRAPH OF LAPPED MOLYBDENUM SURFACE SHOWING PITTING

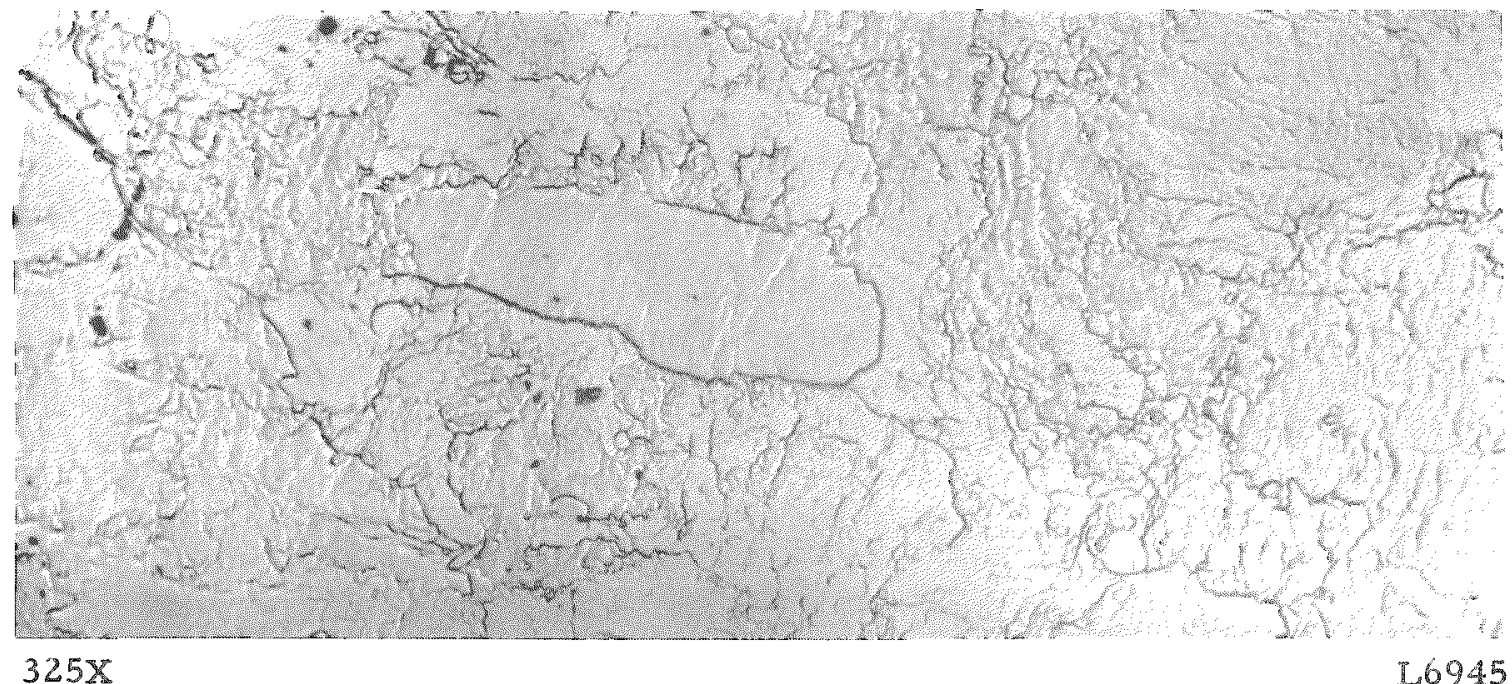

FIGURE 8. LAPPED SURFACE OF MOLYBDENUM AITER ETCHING 


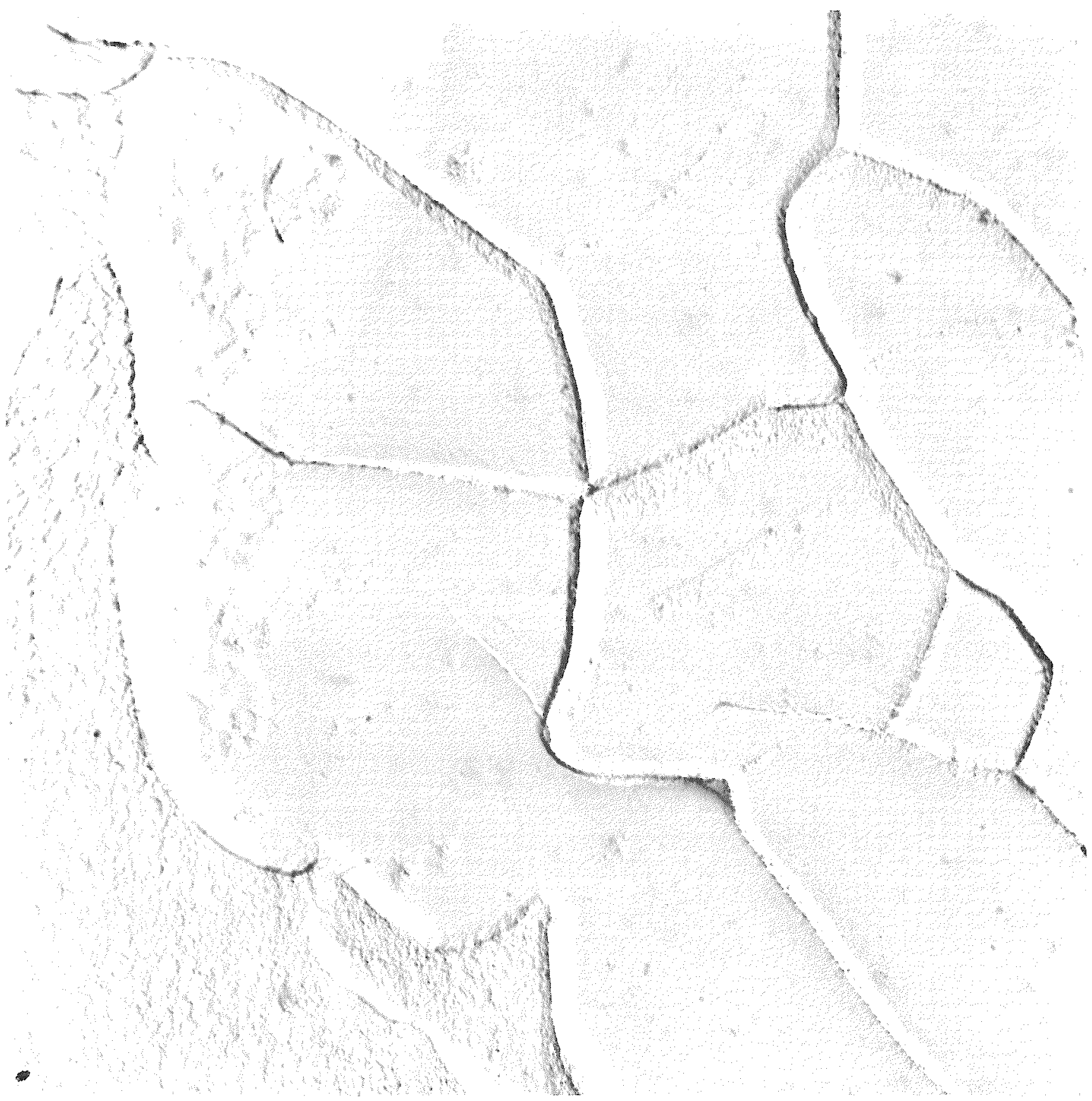

$15,000 \mathrm{X}$

E6654A

FIGURE 9. ELECTRON MICROGRAPH OF ETCHED MOLYBDENUM SURFACE SHOWING STRESS CRACKS 


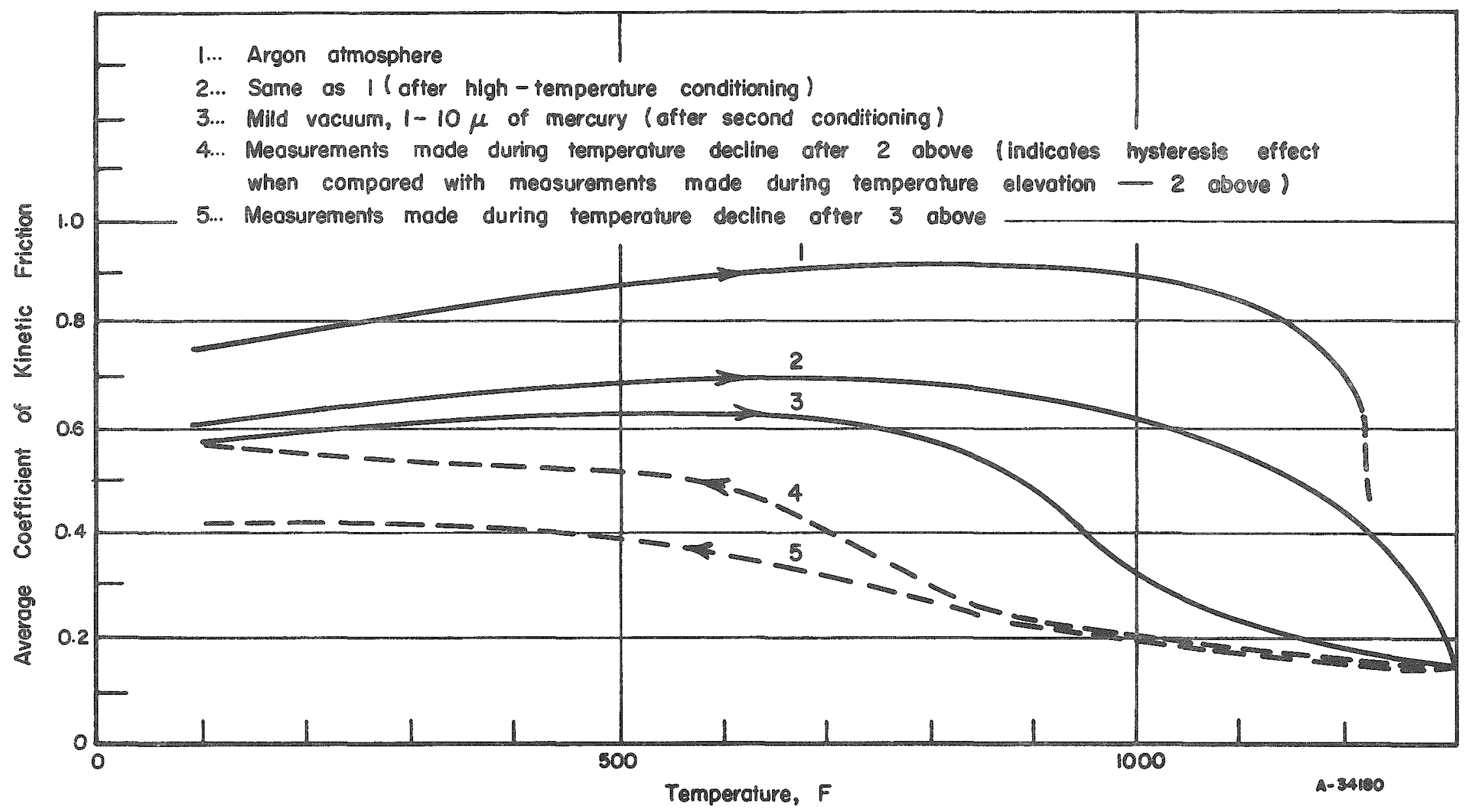

FIGURE 10. SUMMARY OF FRICTION TESTS EMPLOYING MOLYBDENUM SLIDING AGAINST ITSELF WITHOUT LUBRICATION 


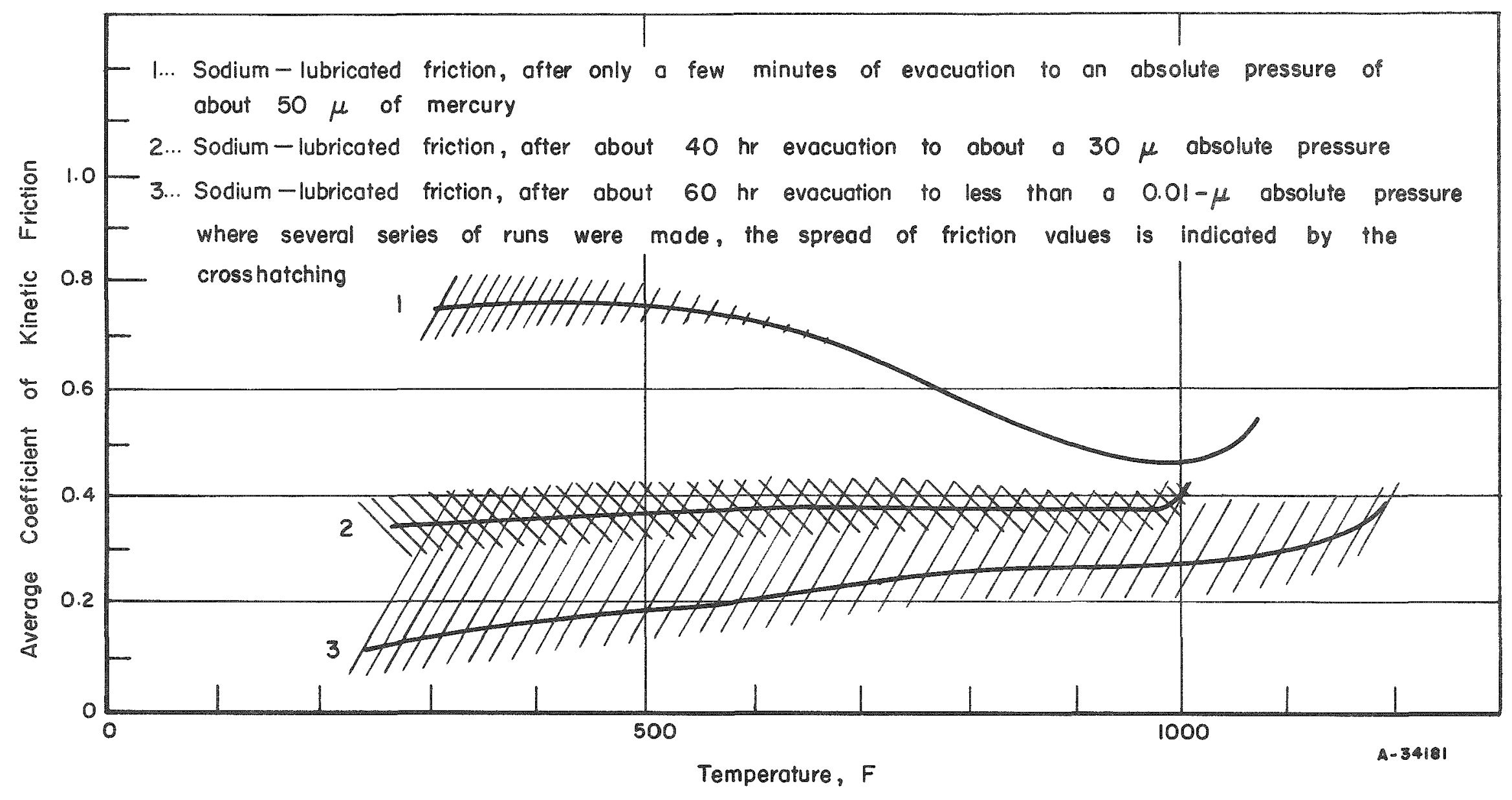

FIGURE 11. SUMMARY OF FRICTION TESTS EMPLOYING MOLYBDENUM SLIDING AGAINST ITSELF WITH SODIUM LUBRICATION 
heated-in-air molybdenum surfaces, whereas $\mathrm{MoO}_{2}$ is found on such surfaces when heated in a vacuum of about $1 \times 10^{-2} \mathrm{~mm}$ of mercury absolute. When specimens were heated to about $1400 \mathrm{~F}$ in such a vacuum, or at lower temperatures in a vacuum of about $5 \times 10^{-6} \mathrm{~mm}$ of mercury absolute, a very diffuse diffraction pattern, possibly from highly strained metallic molybdenum, was observed. Since $\mathrm{MuO}_{2}$ was observed to be produced by conditions similar to those employed during the friction experiments, a differential thermal analysis (DTA) was used to determine whether any ruaction occurred between $\mathrm{MoO}_{2}$ and molten sodium. For this experiment $\mathrm{MoO}_{2}$ powder and solid sodium were loaded at room temperature into a small stainless steel capsule. The loading and subsequent welding shut of the capsule were done in a helium-filled vacuum dry box. This capsule also contained a pair of centrally located thermocouples which were connected with an adjacent exactly similar capsule containing only sodium. When the pair of capsules was heated at a steadily increasing temperature, any sudden difference in their internal temperatures was registered and recorded. By this technique a temperature excursion was found to exist between 700 and $800 \mathrm{~F}$. The peak or maximum point, verifjed when the experiment was repeated, occurred at $775 \mathrm{~F}$. When the material. recovered from the $\mathrm{MoO}_{2}$-sodium capsule was analyzed by X-ray difraction, $\mathrm{Na}_{2} \mathrm{MoO}_{4}$ was found to be present in substantial quantities. A similar differential thermal analysis was performed for molybdenum metal chips immersed in molten sodium. Since no temperature excursion was recorded during this test, it was concluded that no alloying reaction occurred between sodium and molybdenum. It should be emphasized here that the absence of a temperature excursion for the latter analysis does not indicate that no $\mathrm{Na}_{2} \mathrm{MoO}_{4}$ was formed; it indicates that it could only be formed slowly or in relatively small amount. This was verified when $\mathrm{Na}_{2} \mathrm{MOO}_{4}$ was found to be present on lapped surfaces of molybdenum specimens which had been exposed to 500 and $1000 \mathrm{~F}$ sodium for $30-$ min periods.

Posttest Analysis of Friction Specimens

After completion of the friction experiments, the specimens were removed and examined. Except where sodium had been evaporated from its surface, the molybdenum flat specimen appeared as clean and shiny to the naked eye as before the experiment. Debris particles were observed and were presumed to be $\mathrm{Na}_{2} \mathrm{MoO}_{4}$. These particles were later found to be readily removed by an alcohol-and-water wash. The tendency of these particles to become concentrated around grain boundaries is illustrated in Figure 12 .

The more severe wear produced by dry sliding, as compared with sodiumlubricated wear, is illustrated in Figure 13. The wear scar on a 1/4-in. polished molybdenum ball and the wear tracks produced by its sliding on a lapped and etched molybdenum flat are shown in Figure 14. The temperature and environment for each of the successive wear tracks are also listed. Enlarged portions of selected wear tracks from the specimens shown in Figures 13 and $14 \mathrm{~b}$ are exhibited in Figures $15 \mathrm{a}$ and 15b, respectively. The deep galling and tearing damage produced by dry sliding (Figure 15a) stands in bold contrast with the rather superficial scoring produced during sodium-lubricated friction (Figure 15b). These photographs, as well as the electron micrographs, were produced by replica techniques.

Electron micrographs reproduced in Figures 16 and 17 once again make the comparison, at about 10,000X magnification, between wear tracks produced sliding and by sodium-lubricated sliding. It is also apparant from these nicrographs 


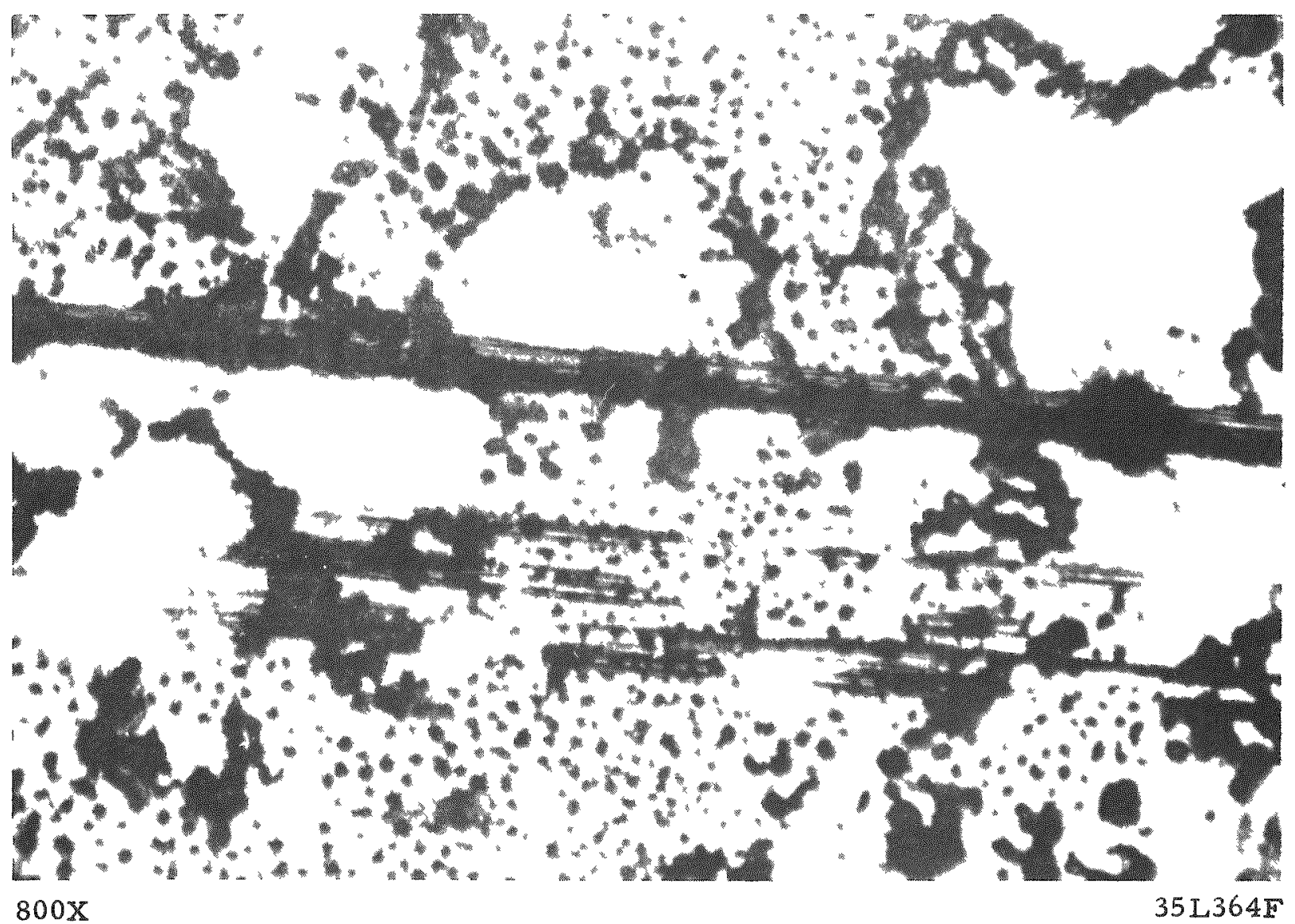

FIGURE 12. DEBRIS PARTICIES AND FRICTION TRACKS EOUND ON AN ETCHED, MOLYBDENUM FLAT SPECIMEN AFTER FRICTION TESTING

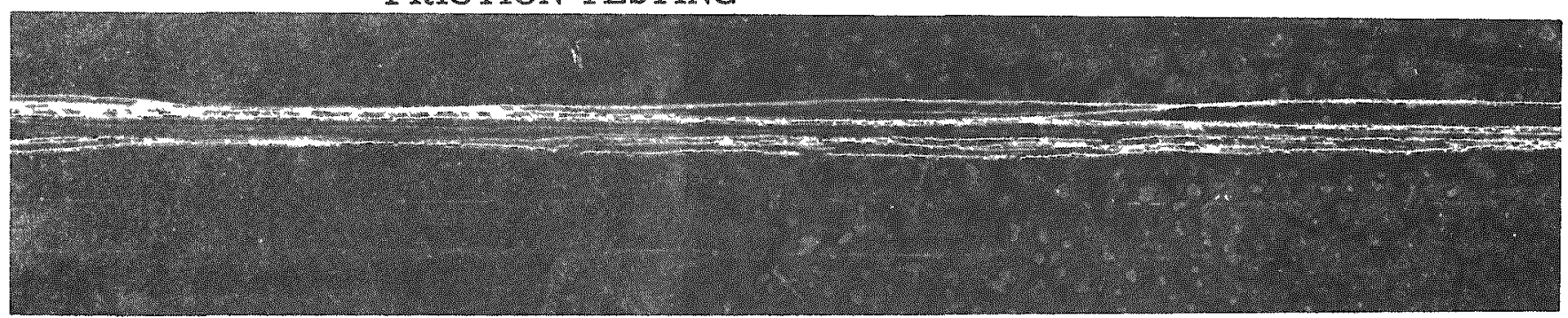

FIGURE 13. WEAR TRACKS PRODUCED ON AN ETCHED AND LAPPED MOLYBDENUM ELAT SPECIMEN IN FRICTION TESTS EMPLOYING NO LUBRICATION AND SODIUM LUBRICATION

The wear tracks produced by dry sliding appear white in the photograph; those produced with sodium lubrication are faintly visible across the lower portion of the photograph. 


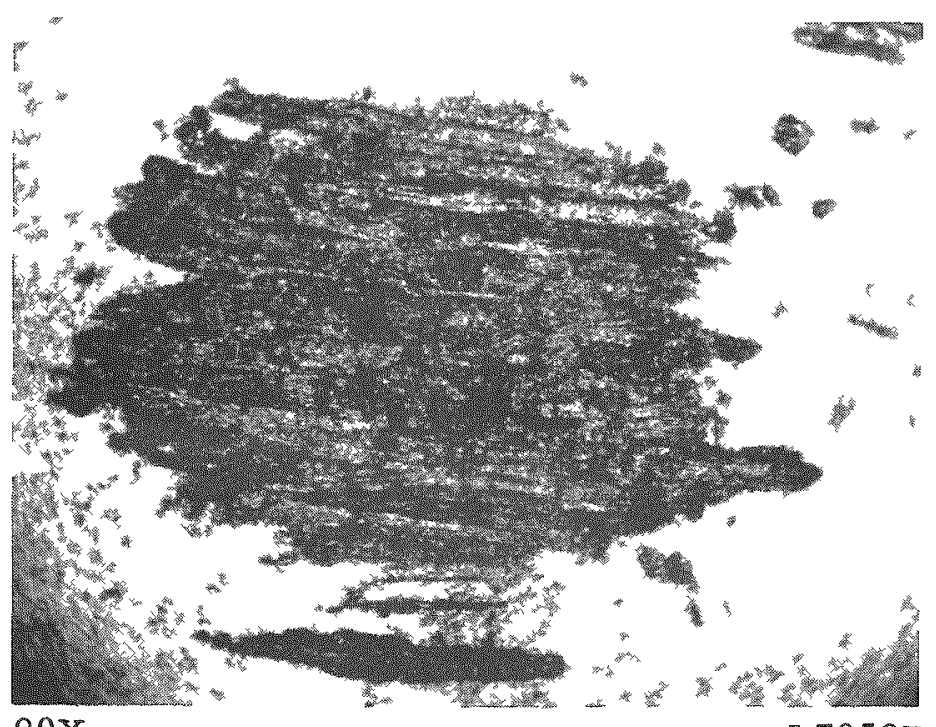

$90 \mathrm{X}$

L7059B

a. Weax Scar Produced on 1/4-In.-Diameter Polished Molybdenum Ball

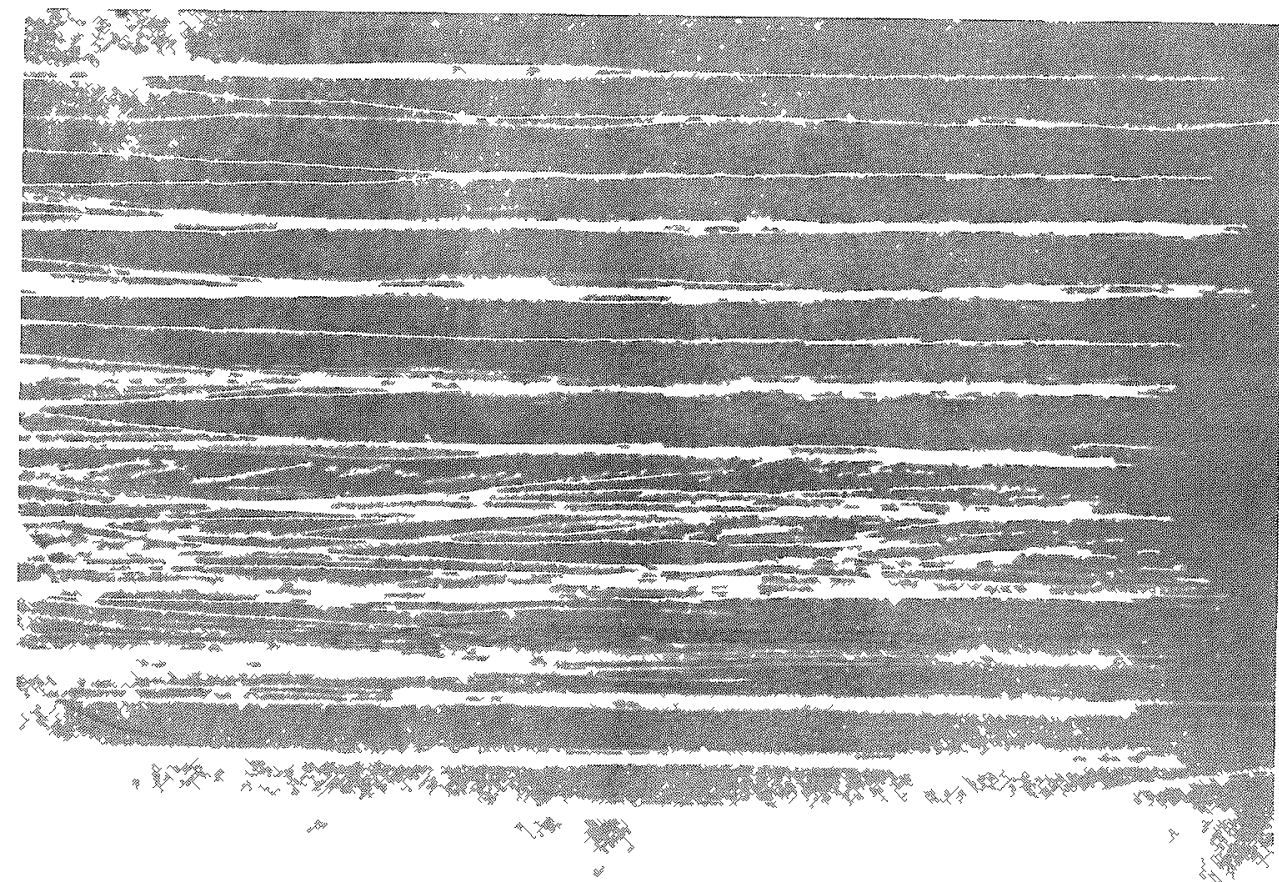

$6 \mathrm{x}$
Temperature,

\begin{tabular}{rrrr}
\multicolumn{1}{c}{$F$} & & Atmosphere \\
\cline { 1 - 1 } 80 & & Vacuum \\
80 & & Vacuum \\
400 & & Vacuum \\
400 & & Vacuum \\
500 & & Vacuum \\
620 & & Vacuum \\
700 & & Vacuum \\
800 & & Vacuum \\
1000 & & Vacuum \\
1200 & & Vacuum \\
1300 & & Vacuum \\
1100 & & Vacuum \\
& & \\
80 & & Vacuum \\
350 & & Argon \\
600 & & Argon \\
80 & & Argon
\end{tabular}

\section{FIGURE 14. WEAR SCARS PRODUCED BY SLIDING A MOLYBDENUM BALL ACROSS A MOLYBDENUM PLATE IN VACUUM OR IN ARGON}

Atmospheres argon, 1 atm, vacuum, $5 \times 10^{-6} \mathrm{~mm}$ of mercury. 


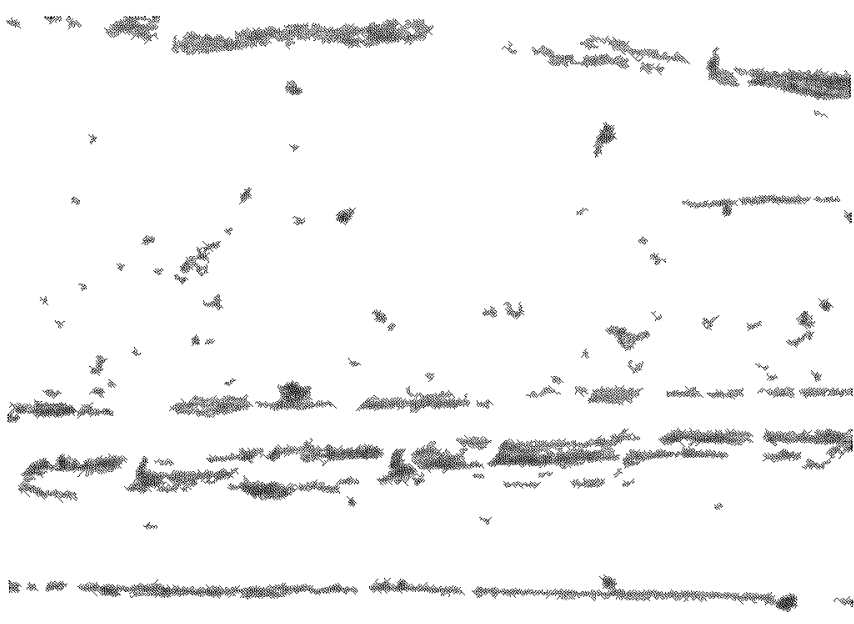

$325 x$

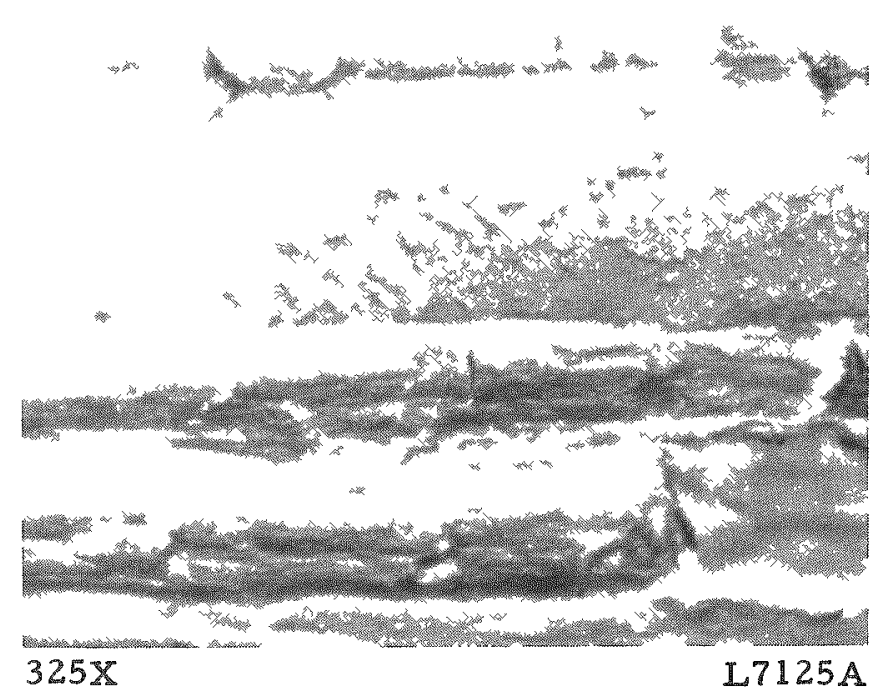

a. Wear Tracks Formed in Vacuum With no Sodium Present

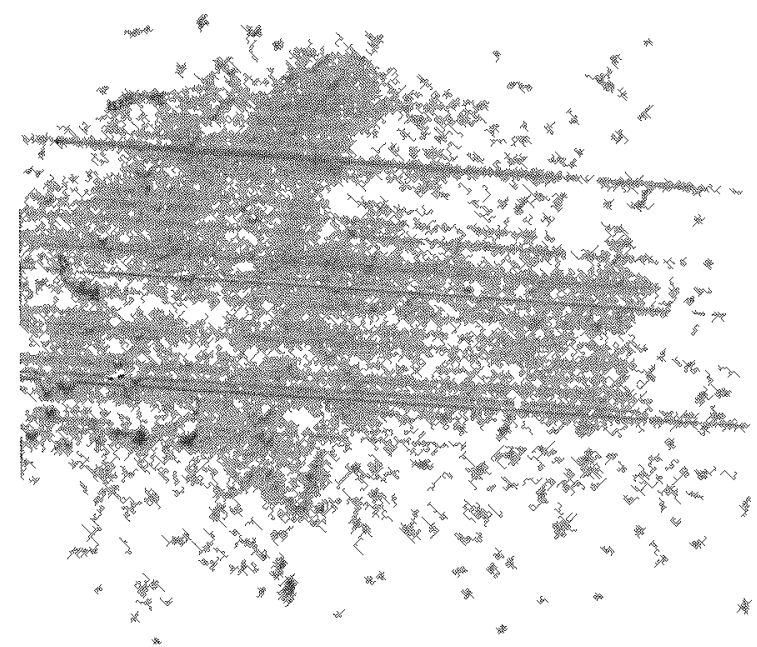

$325 x$

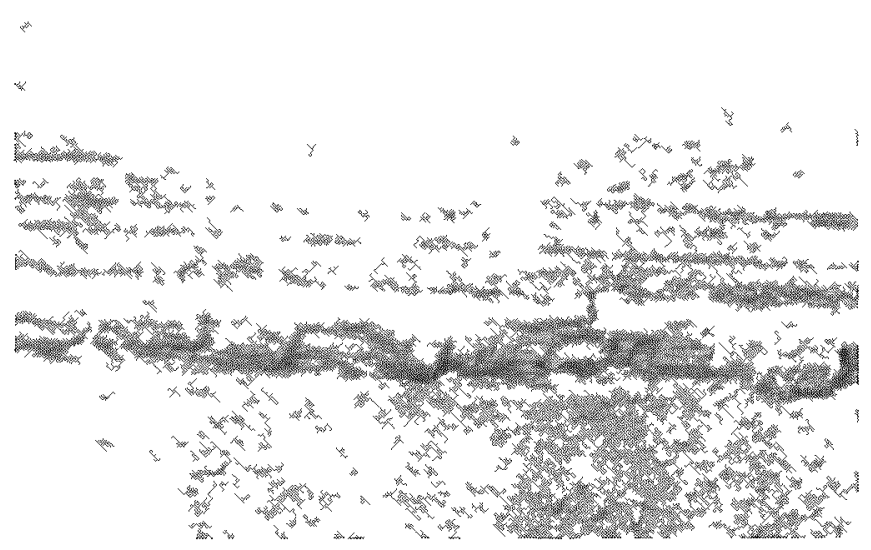

$325 \mathrm{X}$

L7127

b. Wear Tracks Formed in Argon Under Sodium Lubrication

FIGURE 15. WEAR TRACKS PRODUCED ON MOLYBDENUM FLAT SPECIMENS BY A $1 / 4-I N .-D I A M E T E R$ MOLYBDENUM BALL

Atmospheres: argon, 1 atm; vacuum, $5 \times 10^{-6} \mathrm{~mm}$ of mercury. 


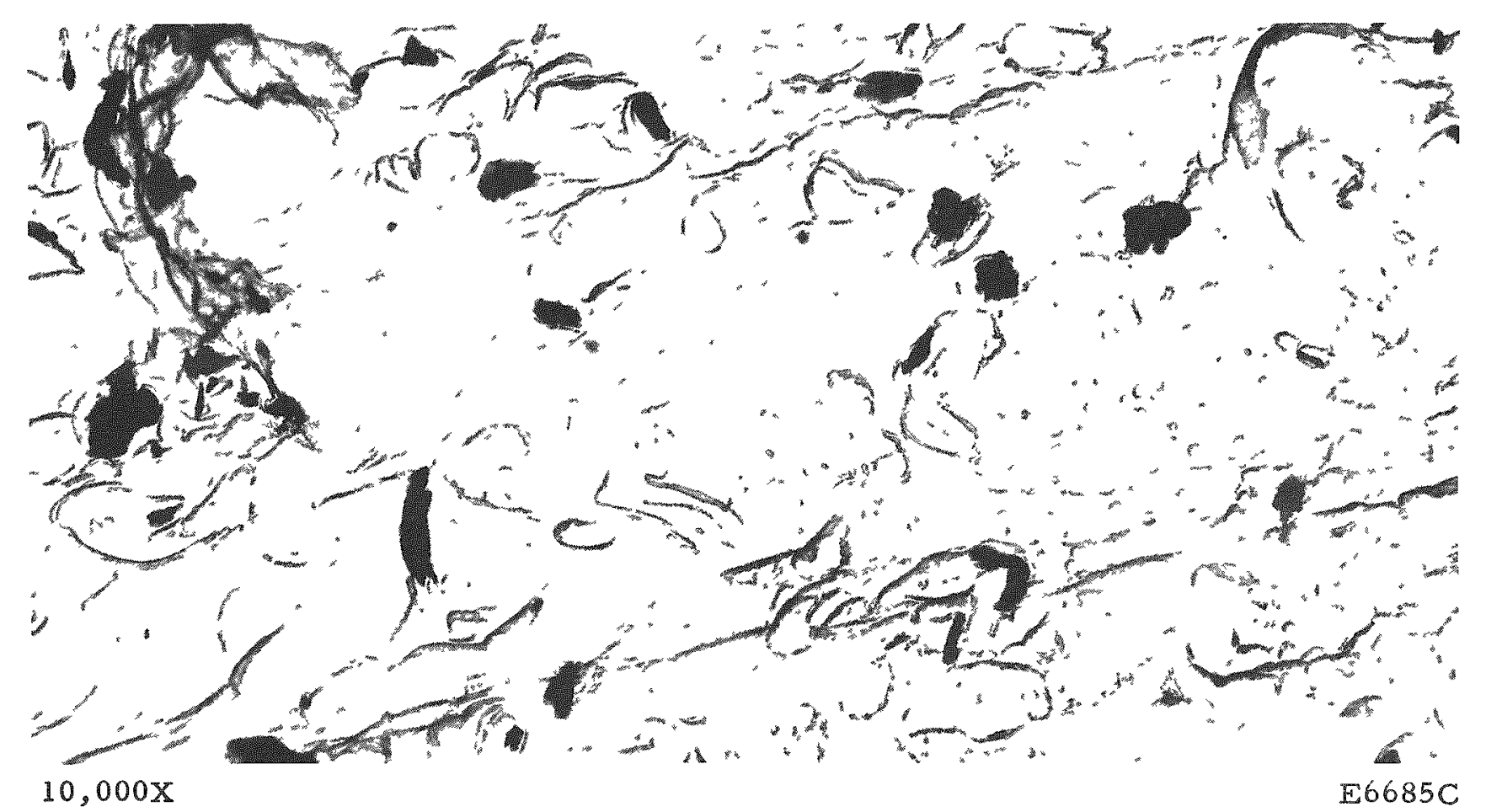

a. Portion of Wear Track Formed in Vacuum With no Sodium Present

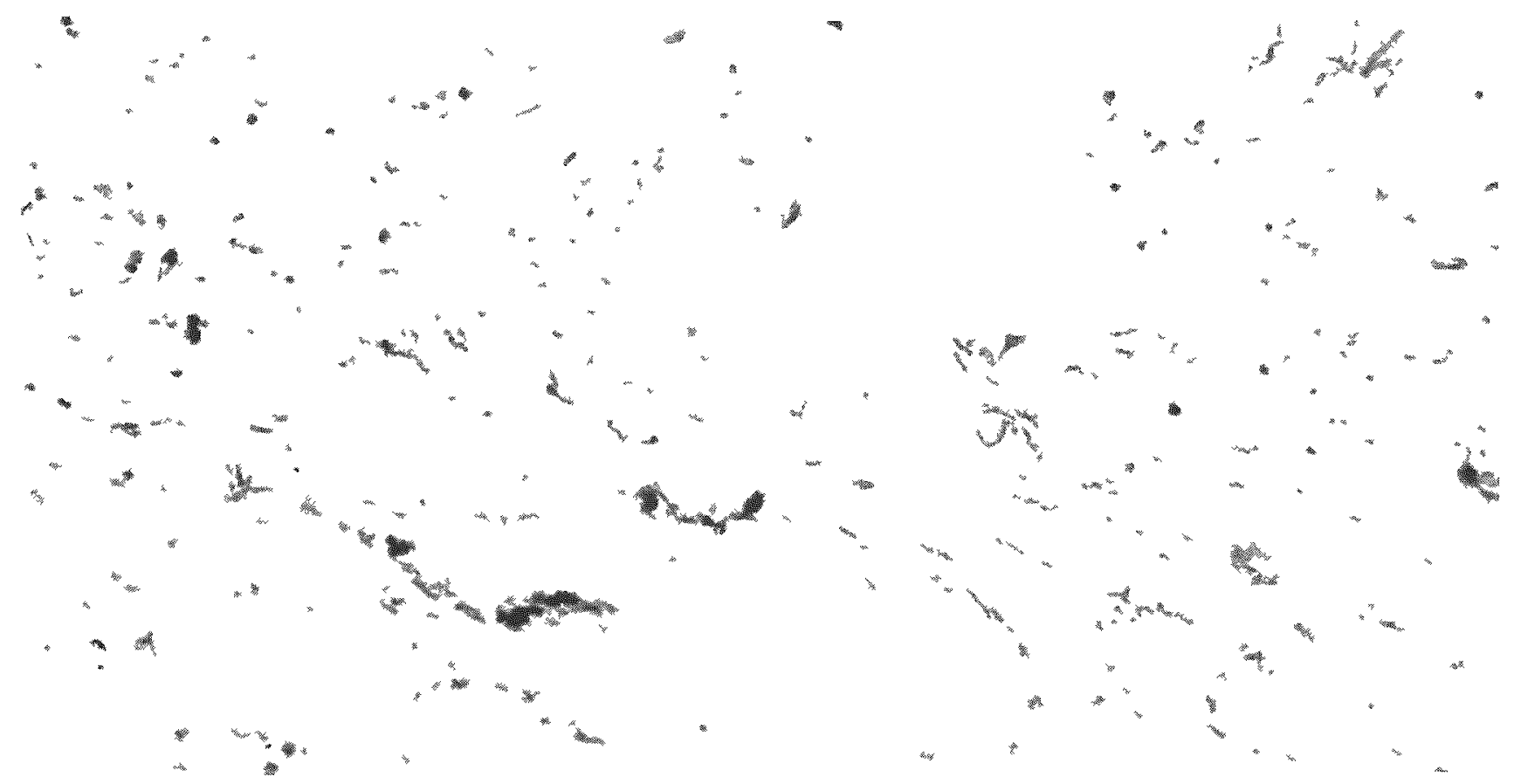

$10,000 x$

E6693E

b. Portion of Wear Track Formed in Argon With Sodium Lubrication

FIGURE 16. ELECTRON MICROGRAPHS OF WEAR TRACKS PRODUCED AT 400 F ON A MOLYBDENUM FLAT BY A 1/4-IN. -DIAMETER MOLYBDENUM BALL 


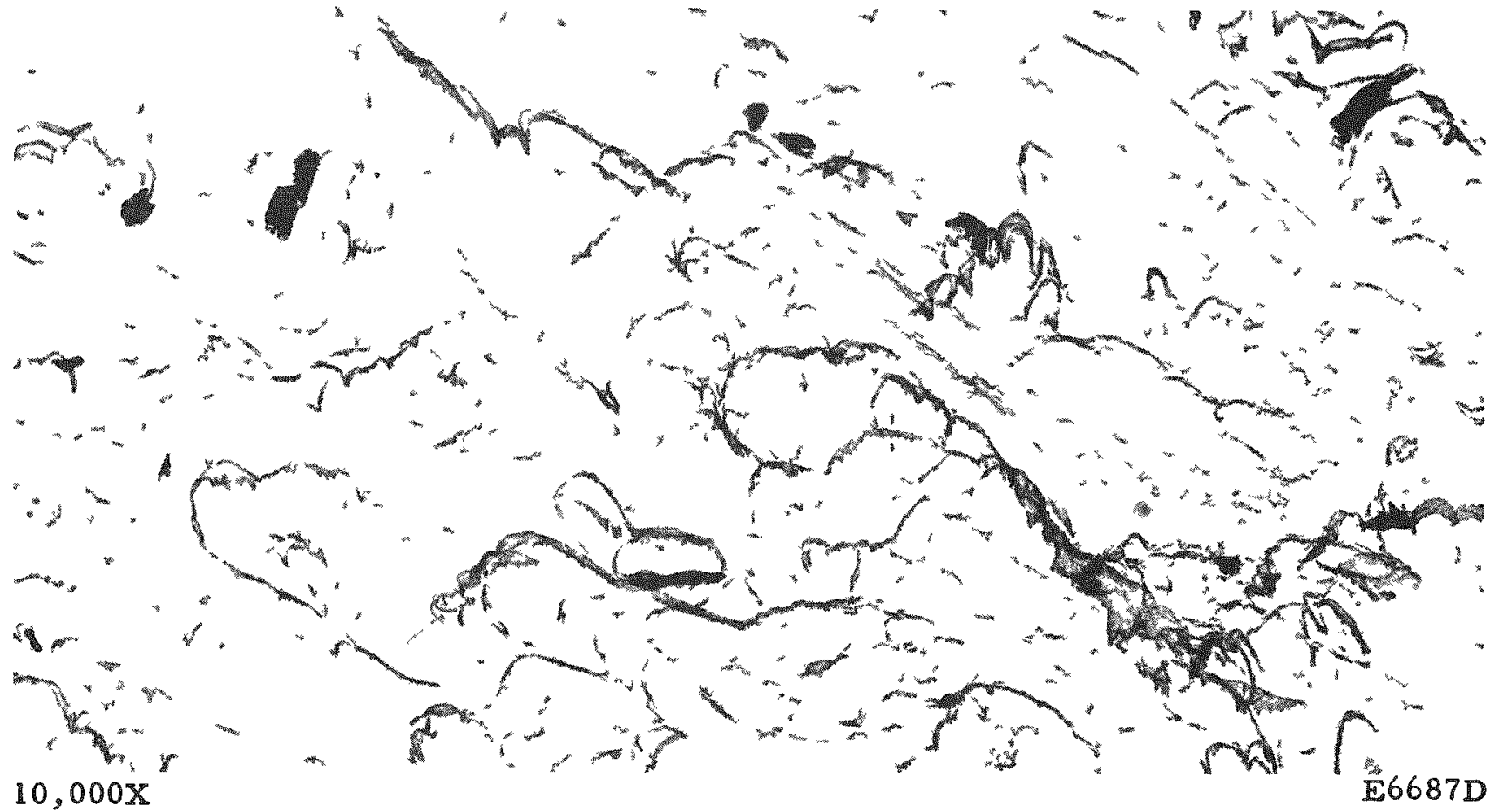

a. Portion of Wear Track Formed at $900 \mathrm{~F}$ in Vacuum With no Sodium Present

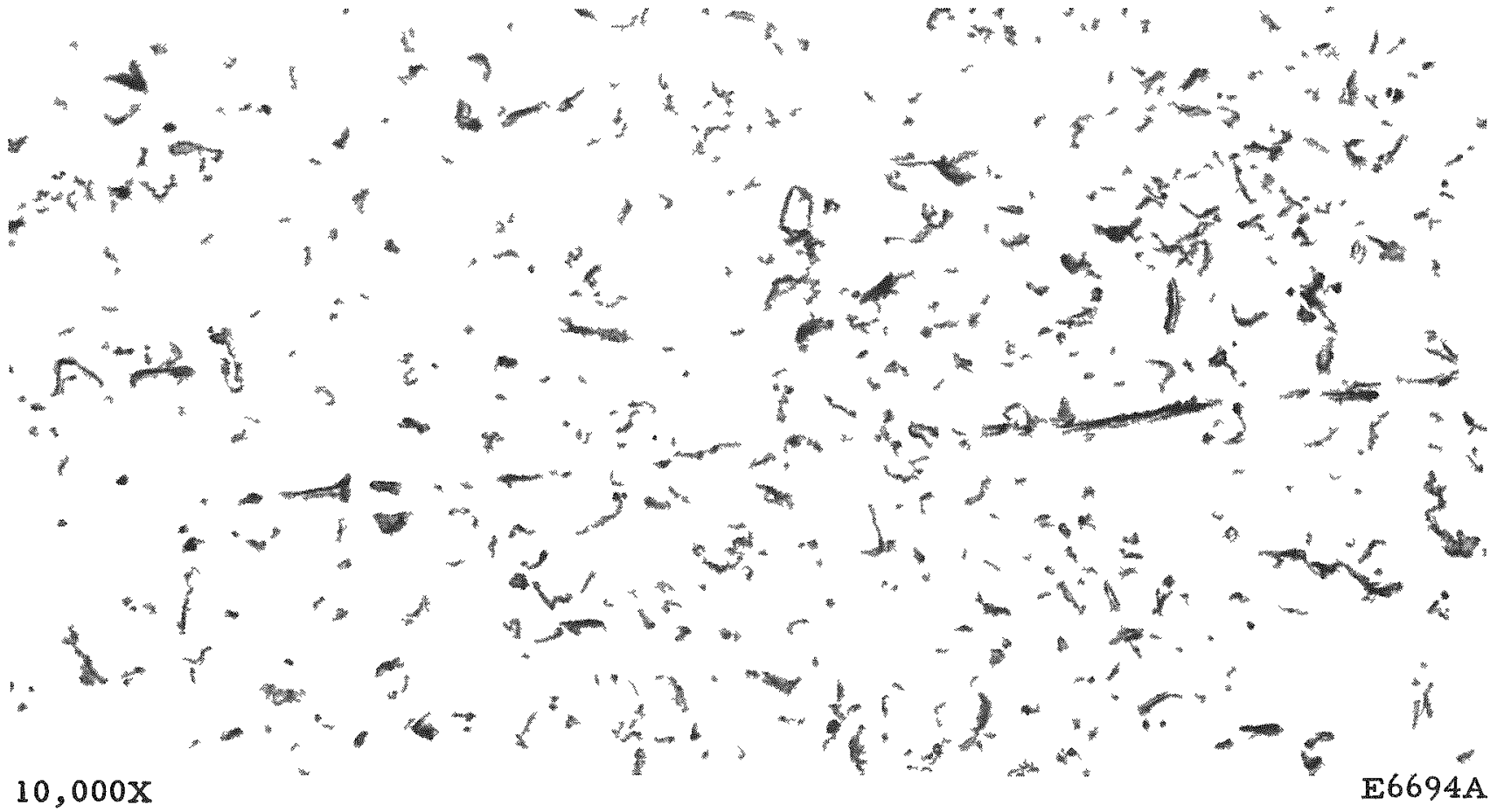

b. Portion of Wear Track Formed at 800 F in Argon Wath Sodium Lubrication FIGURE 17. ELECTRON MICROGRAPHS OF WEAR TRACISS PRODUCED ON A MOLYBDENUM FLAT BY A 1/4-IN. -DIAMETER MOLYBDENUM BALL 
that there is no obvious difference in surface damage between slides made at $400 \mathrm{~F}$ and those made at 800 or $900 \mathrm{~F}$.

These photomacrographs, photomicrographs, and electron micrographs of variously produced wear tracks illustrate marked differences in wear. A quantitative evaluation of wear can also be made using these tools and is being considered for future research.

\section{DISCUSSION}

The study of molybdenum sliding against itself in liquid sodium has yielded some interesting evidence to support a reacted-surface-film hypothesis for the mechanism of lubrication of molybdenum by liquid sodium. The basic premise of this theory is that sodium does not in itself lubricate the surfaces but acts as a moderator of the surface films formed at the sodium-molybdenum interface. Careful analysis of surface chemistry and surface structure of wear specimens suggests that temperature-sensitive surface reactions perhaps associated with the phenomenon of wetting are responsible for observed differences in frictional behavior of sliding molybdenum pairs.

The fact that solid films on the metal surface are influencing wear and friction can be demonstrated by consideration of the frictional behavior of sliding specimens in relation to the chemical makeup of the surfaces after sliding. When pure molybdenum specimens were rubbed in vacuum or in an inert-gas atmosphere, higher friction coefficients were observed for freshly prepared surfaces than for those supposedly degassed by heating in a vacuum. Addition of liquid sodium to the rubbing surfaces in an argon atmosphere further reduced the friction. The friction remained at this level even when the sodium was evaporated from the surfaces. Static oxidation tests revealed that heating molybdenum specimens to $500 \mathrm{~F}$ in air produces an $\mathrm{MoO}_{3}$ film. Heating the specimen in a vacuum of $10^{-5} \mathrm{~mm}$ of mercury reduces the trioxide to $\mathrm{MoO}_{2}$. Further heating in a vacuum of $10^{-6} \mathrm{~mm}$ of mercury removes all detectable traces of the dioxide. A sodium molybdate $\left(\mathrm{Na}_{2} \mathrm{MoO}_{4}\right)$ is formed when oxidized molybdenum is heated in contact with sodium. The rate of this reaction appears to be temperature controlled and may be influenced by the increase of solubility of NaO in sodium at temperatures above $500 \mathrm{~F}$.

In general, friction was high and surface damage severe when $\mathrm{MoO}_{3}$ films were present. The $\mathrm{MOO}_{2}$ films yielded lower friction values, and $\mathrm{Na}_{2} \mathrm{MoO}_{4}$ films were associated with the lowest friction. The presence of $\mathrm{Na}_{2} \mathrm{MOO}_{4}$ was also accompanied by lack of surface damage during sliding. Electron and light micrographs of wear tracks on "clean" molybdenum surfaces showed considerable ploughing and roughening caused by stick-slip behavior or the forming and shearing of metal junctions. Those surfaces with low friction and no stick-slip frictional behavior were smooth and appeared covered with a soft substance - presumably the molybdate.

Evidence that the molybdate reaction was occurring on the molybdenum surface may be found in the photomicrographs of posttest wear surfaces. Figure 12 shows particles of the surface coating concentrated around grain boundaries. Since the grainboundary area of the molybdenum used appeared to contain residual stresses (Figure 9), 
the metal in these regions should have a higher activity than the matrix, and reactions might be expected to originate at the grain boundaries. A more random dispersal of the coating might be expected if it were adsorbed during precipitation from liquid sodium.

The exact nature of the chemical reactions which produce the molybdate film are not known. With the chemical elements molybdenum, oxygen, and sodium* present the following reactions are possible:

$$
\begin{aligned}
& 4 \mathrm{Na}_{2} \mathrm{O}+\mathrm{Mo} \longrightarrow \mathrm{Na}_{2} \mathrm{MoO}_{4}+6 \mathrm{Na} \\
& 2 \mathrm{Na}_{2} \mathrm{O}+\mathrm{MoO}_{2} \longrightarrow \mathrm{Na}_{2} \mathrm{MoO}_{4}+2 \mathrm{Na} \\
& \mathrm{Na}_{2} \mathrm{O}+\mathrm{MoO}_{3} \longrightarrow \mathrm{Na}_{2} \mathrm{MoO}_{4} \\
& 2 \mathrm{Na}+2 \mathrm{MoO}_{2} \longrightarrow \mathrm{Na}_{2} \mathrm{MoO}_{4}+\mathrm{Mo} \\
& 6 \mathrm{Na}+4 \mathrm{MoO}_{3} \longrightarrow \mathrm{Na}_{2} \mathrm{MoO}_{4}+\mathrm{Mo} \\
& \mathrm{Na}+\mathrm{MO} \longrightarrow \mathrm{Na}+\mathrm{Mo}
\end{aligned}
$$

While $\mathrm{Na}_{2} \mathrm{MoO}_{4}$ has been proven to exist as an end product, several progressive reactions may be required before it is produced. The dissolution of $\mathrm{Na}_{2} \mathrm{O}$ by molten sodium and its failure to reprecipitate at lower temperatures probably indicate that $\mathrm{Na} .2 \mathrm{O}$ has been removed from the solution by formation of $\mathrm{Na}_{2} \mathrm{MoO}_{4}$. This is indicated in Equations (1), (2), and (3) above. Whether or not the molybdate would be formed in the absence of oxygen, e.g., between sodium and $\mathrm{MoO}_{3}$ [Equation (5)], is, at present, unknown.

\section{CONCLUSIONS}

In recent years, the importance of surface chemistry in wear and friction phenomena has become increasingly evident. Careful study of the surface reactions between molybdenum, oxygen, and sodium in relation to observed frictional behavior has demonstrated the importance of surface chemistry in liquid-sodium-lubricated systems. It is apparent that beneficial films found in this research required the presence of oxygen in the system. In practice it is possible that oxygen would not be present or would be depleted after a period of time. Under these circumstances, a pre-formed film on bearing parts may be necessary to improved sliding performance.

A similar study of other materials which might be used as bearing materials in liquid sodium might reveal other sodium-modified reactions which could affect the friction and wear of rubbing surfaces in liquid sodium.

Spectrographic analyses showed the following contamination (in ppm):

For the molybdenum: iron, about 10 ; silicon, about 10 .

For the sodium: iron, 10 ; silicon, $<10$; magnesium, $<1$; copper, 2; lead, 3; tin, 0.2 .

Not determined, boron, $<100$; tantalum, $<0.3$. 


\section{REFERENCES}

(1) Taylor, J. W., and Ford, S. D., "Solid Metal-Liquid Metal Interaction Studies, Part II. Contact Angle Relationships for Sodium on Solids", AERE-M/R-1729 (November 19, 1955).

(2) Winkler, H. H., and Vandenburg, L. B., "Method and Results of Sodium Wetting Tests", KAPL-P-231 (December 27, 1949).

JWK/CWM/WAG:nsw 